Article

\title{
Analysis of Streptococcal Infection and Correlation with Climatic Factors in Cultured Tilapia Oreochromis spp. in Taiwan
}

\author{
Pei-Chih Liao ${ }^{1,2}$, Yi-Lun Tsai ${ }^{1}$, Yao-Chung Chen ${ }^{1}$, Pei-Chi Wang ${ }^{1,3,4}$, Shu-Chu Liu ${ }^{5, *(1)}$ and \\ Shih-Chu Chen $1,3,4,6, *$ (D) \\ 1 Department of Veterinary Medicine, College of Veterinary Medicine, National Pingtung University of \\ Science and Technology, Pingtung 91201, Taiwan; liao.js@msa.hinet.net (P.-C.L.); \\ yltsai@mail.npust.edu.tw (Y.-L.T.); r02632007@gmail.com (Y.-C.C.); pc921003@gmail.com (P.-C.W.) \\ 2 Yunlin County Animal and Plant Diseases Control Center, Yunlin 640001, Taiwan \\ 3 Southern Taiwan Fish Diseases Research Center, College of Veterinary Medicine, National Pingtung \\ University of Science and Technology, Pingtung 91201, Taiwan \\ 4 International Degree Program of Ornamental Fish Technology and Aquatic Animal Health, \\ International College, National Pingtung University of Science and Technology, Pingtung 91201, Taiwan \\ 5 Department of Management Information Systems, College of Management, National Pingtung University of \\ Science and Technology, Pingtung 91201, Taiwan \\ 6 Research Center for Animal Biologics, National Pingtung University of Science and Technology, \\ Pingtung 91201, Taiwan \\ * Correspondence: sliu@mail.npust.edu.tw (S.-C.L.); scchen@mail.npust.edu.tw (S.-C.C.)
}

Received: 26 May 2020; Accepted: 8 June 2020; Published: 10 June 2020

\begin{abstract}
Tilapia (Oreochromis spp.), a prominent warm water food fish, is one of the major fish species grown in the aquaculture industry in south-east Asia. Tilapia can tolerate adverse water quality and other stressors, like diverse salinity and fluctuation of $\mathrm{pH}$ value, better than most other commercial aquaculture species. Environmental fluctuations are one of the main factors that affect the outbreak of infectious diseases in cultured tilapia. Cultured tilapia in Taiwan appears to be more susceptible to infections caused by Streptococci during the summer season. The present study emphasizes the Streptococcus spp. infection in tilapia in Taiwan and is the first study on the analysis of the potential impact of climate change on streptococcal infection in cultured tilapia in Asia. The data collected from the treatment and diagnosis system (TDS) of the aquatic animal diseases database from 2006 to 2015 were used to analyze the endemic streptococcal infection and the effect of climatic factors. Based on the results, the factor, average atmospheric pressure, is negatively correlated to streptococcal infection, while the other three, including average temperature, ultraviolet (UV) index, and rainfall, are positively correlated to streptococcal infection. A multivariate logistic regression model with these four factors was also built. When the average temperature is above $27.0{ }^{\circ} \mathrm{C}$, the average atmospheric pressure is lower than $1005.1 \mathrm{hPa}$, or the UV index is above 7.2 , the percentage of cumulated positive farms from all submitted tilapia cases was more than $50 \%$. In addition, within 3 days of rain, rainfall is relevant to the occurrence of Streptococcus in tilapia. Using TDS to alert the occurrence of streptococcal infection in tilapia can be a very useful tool for veterinary aquatic animal inspection stations, and reducing economic losses and labour costs in aquatic agriculture.
\end{abstract}

Keywords: Streptococcus spp.; Tilapia (Oreochromis spp.); temperature; atmospheric pressure; UV

\section{Introduction}

Tilapia (Oreochromis spp.) is one of the important farmed fish species in Taiwan, accounting for approximately 70,000 metric tons from the annual report for fisheries statistics, Fisheries Agency, 
Council of Agriculture, Taiwan [1]. The demand for tilapia from domestic markets as well as from international markets has increased two-fold since the last decade. Tilapia can tolerate adverse water quality and other stressors better than most other commercial aquaculture species. Tilapia is one of the fastest growing fish, increasing its compatibility for intensive farming. The intensive farming of tilapia with high stocking density in Taiwan has increased immensely, allowing the adaptability effects of climate change and food shortages. However, high stocking rates make intensive and semi-intensive farms more susceptible to infectious diseases [2].

The first report on streptococcal infection in Taiwan can be traced back to 1985 [3] in cage-cultured tilapia, while the first case report on streptococcosis was recorded in 1954 from a Japanese rainbow trout farm [4]. After the first case was announced in Japan in 1958, streptococcosis gradually spread to other parts of the world, infecting almost all major cultured species, and thus came to be recognized as a major fish disease. In streptococcaceae, a family of Gram-positive bacteria, pathogens isolated from diseased fish include mainly S. agalactiae, S. iniae, S. dysgalactiae, and Lactococcus garvieae, and some minors such as L. lactis, L. piscium, and S. parauberis.

Recently, some reports revealed that $S$. agalactiae cause serious economic loss in aquaculture in tilapia and other fish species in Taiwan with a host range from freshwater to seawater fish, including tilapia, ayu, eels, mullet, bass, catfish, ornamental fish, and wild fish, as well as shrimp and bullfrogs [5-7]. Due to economic concerns, tilapia is usually cultured at high density, increasing stress levels, which may lead to decreased immunity and a decreased survival rate [8]. Streptococcus spp. are ubiquitous in water and can also be isolated from healthy fish; leading to false diagnosis of infectious strains. Tilapia may become infected by streptococcosis due to several reasons, including stress. The symptoms of infection in tilapia include weakness, loss of appetite, abnormal swimming behaviour, exophthalmia, intra-ocular haemorrhage or opacification, convex and bleeding eyes, haemorrhage of muscle, anus and fin base [9], lesions including gill telangiectasia, haemorrhage, ascites, and kidney, spleen, and liver enlargement or whitish pinpoint necrosis $[9,10]$.

The impact of climate change attracts people's attention recently, but the related studies were very limited in the aquatic animals. In Finland, the increasing of water temperature was found to be correlated to the high parasite infection rate, and considered to affect the diversity of aquatic animals, including their breeding, migration, growing behaviour, feeding, and metabolism [11,12]. In an experimental study, it was also concluded that a sudden increase or decrease in environmental temperature can lead to a significant decrease in the number of white blood cells in tilapia fish, indicating the cause for higher susceptibility to streptococcal infection [13].

The aim of this study was to collect farmed tilapia disease data from different Taiwan veterinarian aquatic animal inspection stations from 2006 to 2015, and examine the occurrence of streptococcosis with respect to temperature fluctuations and other parameters. These findings will fulfil the needs for an early disease warning and management model for tilapia farms and help reduce the economic losses to tilapia aquaculture farms in Taiwan.

\section{Materials and Methods}

\subsection{Collection of Fish Farm Data and Meteorological Data}

At present, each county and city government has aquatic animal disease inspection stations set up in farming areas, and trained and licensed veterinarians are hired to provide free medical examination services. The treatment and diagnosis system (TDS), an online data collection system developed by our research team in 2006 [14] (Figure 1), is used for data recording and case management.

Farm information, such as diagnostic record, farm location, pond size, farming practice, and clinical diagnosis were collected in this system from 2006 to 2015. Fish farmers are accustomed to sending cases to these inspection stations when they have problems, so the data in the TDS system are complete and representative. The meteorological data were collected on the day of each fish farm's case submission. The data source was the national weather station closest to the farm. 


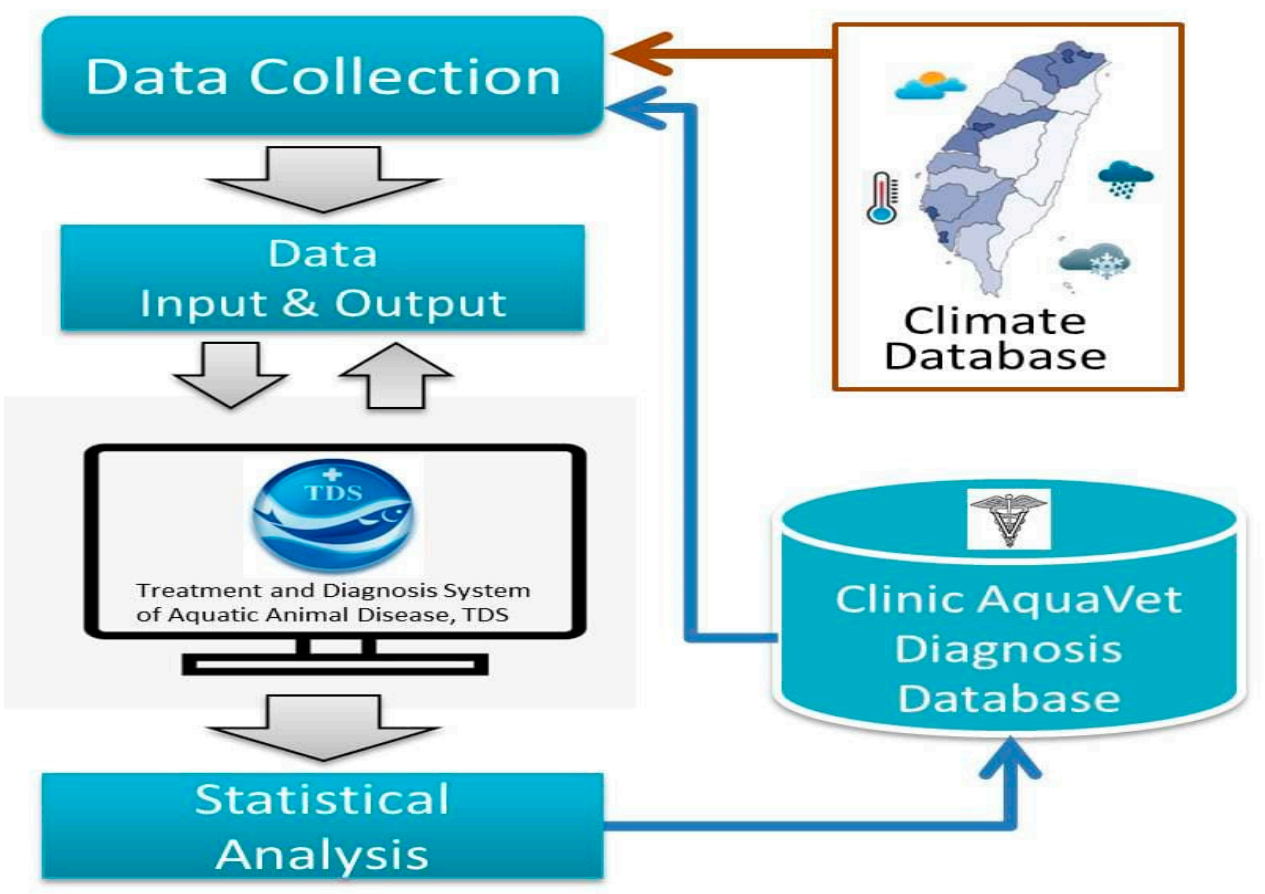

Figure 1. The structural diagram of the treatment and diagnosis system (TDS) shows how the system analyzes data and provides information for clinical diagnosis. TDS integrates climate data from the weather station (climate database) and clinical data from the veterinarian (clinical AquaVet) to do statistical analysis. The result of statistical analysis can predict which factors are risk factors to specific diseases in aquaculture, which can provide information to the veterinarians in the front line. TDS also provides registered member inquiry service (reverse arrow).

\subsection{Identification of Streptococcosis}

The isolation of suspected Streptococcus spp. was carried out at aquatic animal inspection stations. To confirm streptococcosis, clinical signs and gross pathology was performed to check for lesions which are typical symptoms of streptococcosis. In addition, the organ smear from the spleen of diseased tilapia was used for the identification of Streptococcus, as well as colony characteristics, cell morphology and some of the organisms were confirmed by polymerase chain reaction. For each farm, at least three fish must be submitted to the inspection stations. A farm having any tilapia identified Streptococcus spp. positive was defined as a positive farm.

For the species-specific 16S rRNA gene of Streptococcus iniae, PCR methods are carried out using specific primes which are forward primers: Sin-1 [5'-CTAGAGTACACATGTACT (AGCT) AAG-3'] and Sin-2 5'-GGATTTTCCACTCCCATTAC-3'). Fragments are produced by the PCR assay. The method allows for specific identification and produced a $300 \mathrm{bp}$ amplicon [15]. The glyceraldehyde-3-phosphate dehydrogenase gene sequence of Streptococcus agalactiae is selected and amplified by PCR using the specific primer SA-GAPDH-F2:ACAACACATCCATGAAAATG and SA-GAPDH-R1:ATTTACTTCTT CGACAGTTACGTC. The result of PCR assay shows the amplification of $460 \mathrm{bp}$ for S. agalactiae. The species-specific ITS region between the 16S-23S rRNA gene in Streptococcus dysgalactiae is useful for the detection by PCR using forward primer 50-TGGAACA CGTTAGGGTCG-30 (STRDDy I) and reverse primer 50-CTTAACTAGAAAAACTCTTGATTA TTC-30 (dys-16S-23S-2) [16,17]. The fragment produced by the PCR assay is $259 \mathrm{bp}$ in size.

The 16S rRNA gene sequence of Lactococcus garvieae is selected and amplified by PCR using specific primers, pLG-1 (5'-CATAACAATGAGAATCGC-3') and pLG-2 (5'-GCACCCTCGCGGGTTG-3'). The result of the PCR assay shows the amplification of a $1100 \mathrm{bp}$ band [18]. The species-specific ITS region between 16S-23S rRNA gene spacer regions uses synthetic oligonucleotide primers developed by Jensen et al. [19] (G1: 5'-GAAGTCGTAACAAGG-3'; L1: 5'-CAAGGCATCCACCGT-3') were 
employed to amplify the $16 \mathrm{~S}$ to $23 \mathrm{~S}$ rDNA intergenic spacer region. The result of the PCR provides a $380 \mathrm{bp}$ band for Lactococcus. lactis subsp. lactis [20].

\subsection{Analysis of Climatic Factors}

The data of submitted cases located on the geographic area at a latitude of $23^{\circ} 13^{\prime} 48.3 \sim 23^{\circ} 50^{\prime} 36.2$ and longitude of $120^{\circ} 14^{\prime} 03.8 \sim 120^{\circ} 38^{\prime} 40.3$ were recruited in the climatic factor analysis. The submitted tilapia farms with at least one tilapia which detected Streptococcus spp. were classified as "Streptococcal positive farm (=1)"; as well, farms with no tilapias detected Streptococcus spp. were defined as "Streptococcus negative farm $(=0)$ ". The potential climatic risk factors, including average atmospheric pressure $(\mathrm{hPa})$, high and low pressure difference $(\mathrm{hPa})$, average temperature $\left({ }^{\circ} \mathrm{C}\right)$, high and low temperature difference $\left({ }^{\circ} \mathrm{C}\right)$, and UV index and rainfall, were chosen for further analysis. Univariate logistic regression analyses were firstly used to examine the impact of the climatic factors on the infection rate of disease. If the results were of statistical significance ( $p$-value less than 0.05 ), a multivariate logistic regression model was performed. The linear regression models of the percentage of cumulated positive farms from all submitted tilapia cases related to those variables with significant results of univariate models were also performed.

\section{Results}

\subsection{Infection Rate of Diseases}

A total of 3848 tilapias, Oreochromis spp., clinical cases have been collected in a decade. The majority of these cases are bacterial infections (2117/3848), followed by other reasons such as poor water quality (1137/3848), parasitic infections (560/3848), fungal infections (21/3848), and viral infections (13/3848). Among all bacterial infection cases, streptococcosis accounted for 53.7\% (1136/2117) and the infection rate of streptococcosis in tilapia was $29.5 \%$ (1136/3848), with a range of $18.6 \%$ to $37.4 \%$. The cases of Streptococcus with Trichodina and Streptococcus with Aeromonas co-infection in diseased tilapia are $8.1 \%$ (92/1136) and 3.3\% (37/1136), respectively. The clinical symptoms of typical streptococcal infections included exophthalmos, abdomen haemorrhage, anus haemorrhage and ascites. Gram-positive cocci were detected in a smear of the lesion from diseased tilapia (Figure 2).
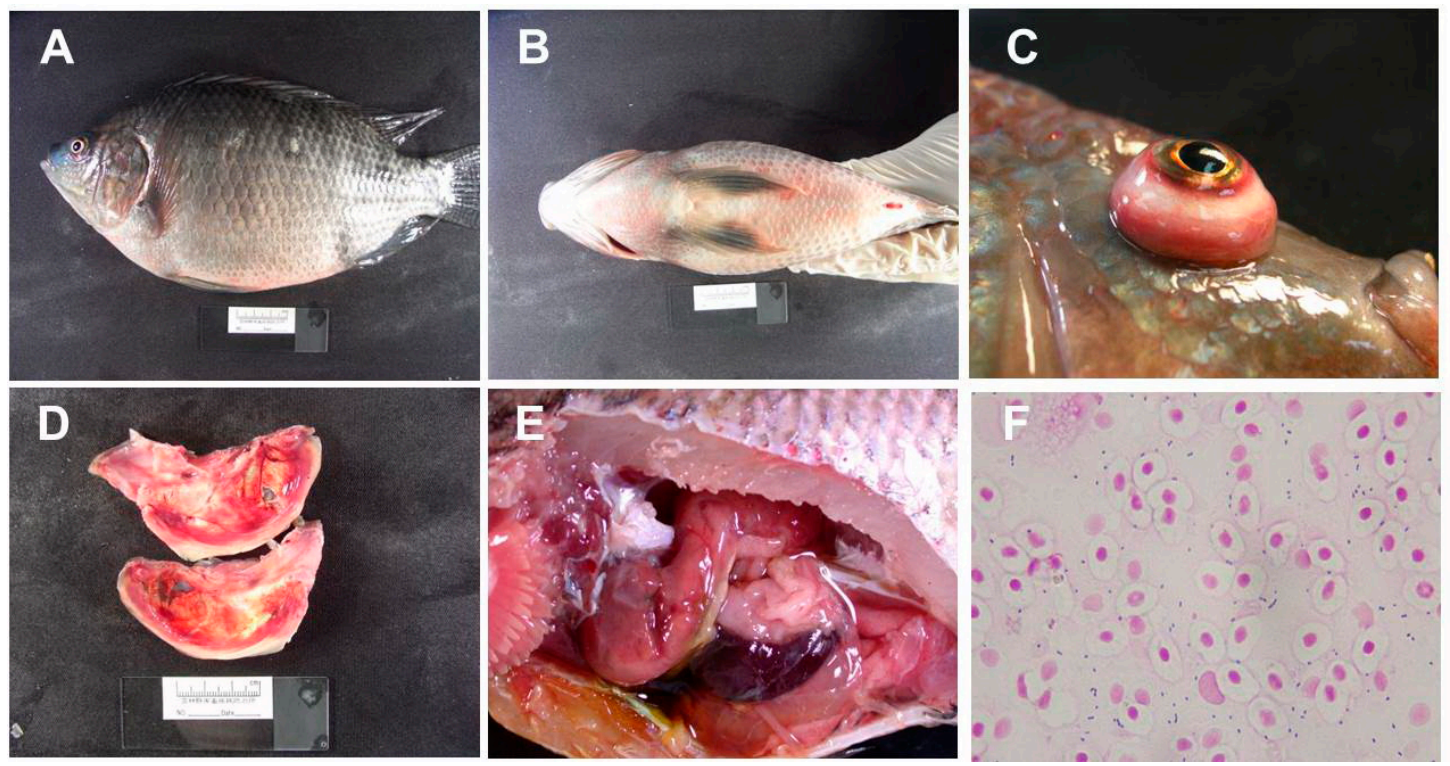

Figure 2. Gross lesions of streptococcosis in Tilapia: (A) skin hemorrhage; (B) abdominal and anus hemorrhage; (C) eye exophthalmos and hemorrhage; (D) inner opercular hemorrhage; (E) ascites and splenomegaly; (F) cocci bacteria in smear from spleen with Gram stain. 
The cumulated infection rate of tilapia streptococcosis in each month throughout a decade (2006-2015) is shown in Figure 3. Data shows a peak of cumulated infection rate from July to September, which reaches $47.1 \%$ in July. The infection rate and cumulative infection rate of tilapia streptococcosis in Taiwan during 2006-2015 are shown in the Figure 4. A high infection rate peak every three years is observed and the cumulative infection rate of tilapia streptococcosis shows the trend of increasing from $23.3 \%$ (2006) to $29.5 \%$ (2015).

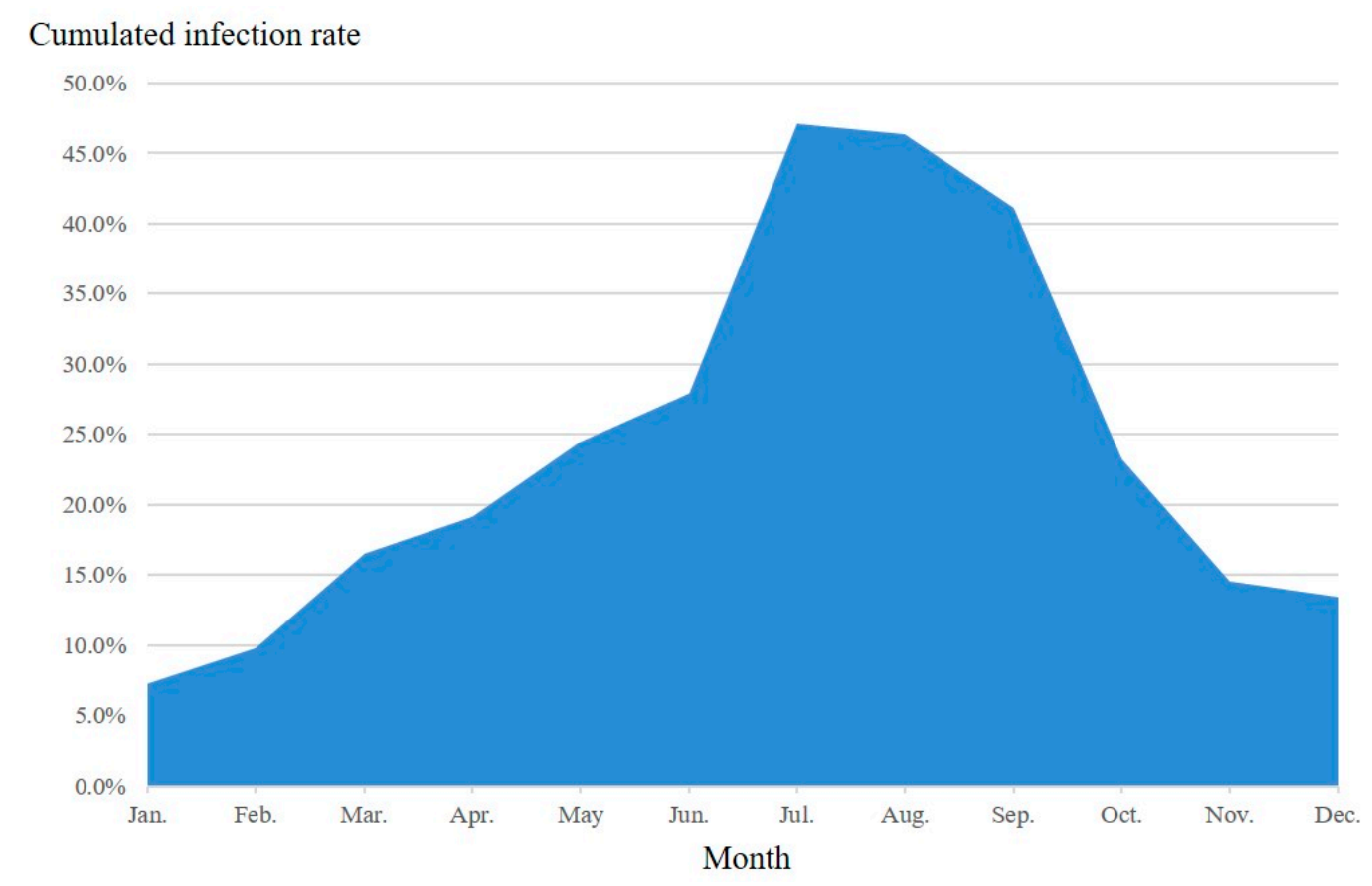

Figure 3. The cumulated infection rate of tilapia streptococcosis in each month throughout a decade (2006-2015).

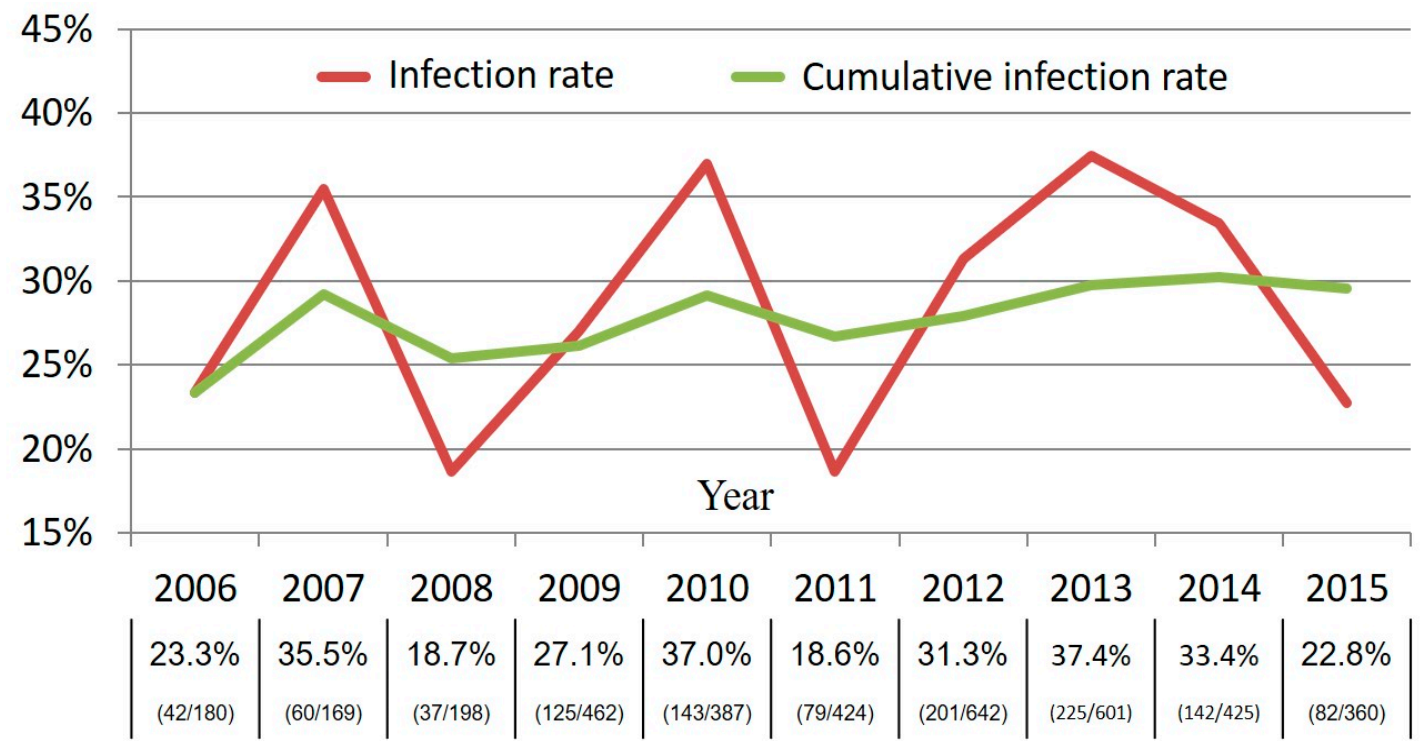

Figure 4. The infection rate and cumulative infection rate of tilapia streptococcosis in Taiwan during 2006-2015. It is observed that high infection rate peaks every three years and the cumulative infection rate of tilapia streptococcosis shows the trend of increasing from $23.3 \%$ (2006) to $29.5 \%$ (2015). 


\subsection{Identification of Streptococcus spp.}

All Streptococcus-like organisms were confirmed by formation of whitish pinpoint colonies on TS agar plates, and blood agar plates. Then, the presence of Gram-positive cocci chains was confirmed by light microscope. Bacteria are without oxidase/catalase. Some isolates from different Taiwan veterinarian aquatic animal inspection stations were identified as species of Streptococcus and Lactococcus. A total of 265 Gram-positive cocci were isolated from diseased tilapia from 2013 to 2015. Bacteria were confirmed by PCR. The results showed that there were five species of Gram-positive cocci, followed by Streptococcus agalactiae [203/265 (76.7\%)], Streptococcus iniae [57/265 (21.5\%)], Lactococcus garvieae [3/265 (1.1\%)] Streptococcus dysgalactiae [1/265 (0.4\%)] and Lactococcos lactis subsp. lactis [1/265 $(0.4 \%)]$ (Table 1$)$.

Table 1. Identification of Gram-positive cocci isolated from Tilapia from 2013 to 2015.

\begin{tabular}{ccccccc}
\hline Year & No. of Total Bacteria & S. agalactiae & S. iniae & S.dysgalactiae & L. garvieae & L. lactis \\
\hline 2013 & 25 & 24 & 1 & 0 & 0 & 0 \\
2014 & 82 & 37 & 42 & 1 & 2 & 0 \\
2015 & 158 & 142 & 14 & 0 & 1 & 1 \\
Total (\%) & 265 & $203(76.7)$ & $57(21.5)$ & $1(0.4)$ & $3(1.1)$ & $1(0.4)$ \\
\hline
\end{tabular}

\subsection{Analysis of Climatic Factors in Infection Rate of Tilapia Streptococcosis}

The results of univariate logistic regression analysis indicate that four climatic factors (average atmospheric pressure, average temperature, UV index and rainfall) significantly related to streptococcal infection (Table 2). The multivariate logistic regression models with these four factors were then built as shown in Table 3. The factor average atmospheric pressure is negatively $(\operatorname{Exp}(B)=0.958)$ correlated to streptococcal infection, while the other three, including average temperature, UV index, and rainfall, are positively $(\operatorname{Exp}(B)=1.014,1.071$, and 1.384, respectively) correlated to streptococcal infection. However, the results were not statistically significant. For the factor of rainfall, the climatic data on the case were submitted on the day and a few days ( 3,5 and 10 days) before the case submitted day was analysed. The results showed that if it rains on the case submitted day or three days before, the submitted case is more likely to be positive of streptococcosis (Table 4).

Table 2. Univariate logistic regression analysis on tilapia streptococcosis and climatic factors.

\begin{tabular}{cccccccc}
\hline Climate Factor & B & S.E. & df & Sig. & Exp (B) & \multicolumn{2}{c}{ 95.5\% C.I. EXP (B) } \\
\hline $\begin{array}{c}\text { Average atmospheric } \\
\text { pressure }(\mathrm{hPa})^{*}\end{array}$ & -0.072 & 0.018 & 1 & 0.000 & 0.931 & 0.899 & 0.964 \\
$\begin{array}{c}\text { High and low pressure } \\
\text { difference (hPa) }\end{array}$ & -0.114 & 0.092 & 1 & 0.213 & 0.892 & 0.745 & 1.068 \\
$\begin{array}{c}\text { Average temperature }\left({ }^{\circ} \mathrm{C}\right) \\
\text { High and low temperature } \\
\text { difference }\left({ }^{\circ} \mathrm{C}\right)\end{array}$ & 0.086 & 0.025 & 1 & 0.001 & 1.090 & 1.038 & 1.144 \\
$\quad$ UV Index * & 0.026 & 0.041 & 1 & 0.530 & 1.026 & 0.947 & 1.112 \\
Rainfall * & 0.121 & 0.037 & 1 & 0.001 & 1.128 & 1.050 & 1.212 \\
\hline & & 0.203 & 1 & 0.016 & 1.630 & 1.095 & 2.426 \\
\hline
\end{tabular}

The linear regression models of the percentage of cumulated positive farms from all submitted tilapia cases related to the changing of average temperature, average atmospheric pressure and UV index are shown in Figure 5. When the average temperature is above $27.0^{\circ} \mathrm{C}$, the average atmospheric pressure is lower than $1005.1 \mathrm{hPa}$, or the UV index is above 7.2, the percentage of cumulated positive farms from all submitted tilapia cases was more than $50 \%$. 
Table 3. Multivariate logistic regression analysis on tilapia streptococcosis and climatic factors.

\begin{tabular}{cccccccc}
\hline Climate Factor & B & S.E. & df & Sig. & Exp (B) & \multicolumn{2}{c}{$\mathbf{9 5 . 5 \% \text { C.I. EXP(B) }}$} \\
\cline { 5 - 8 } & & & & & & Lower & Upper \\
\hline $\begin{array}{c}\text { Average atmospheric } \\
\text { pressure (hPa) }\end{array}$ & -0.043 & 0.026 & 1 & 0.090 & 0.958 & 0.911 & 1.007 \\
Average temperature $\left({ }^{\circ} \mathrm{C}\right)$ & 0.014 & 0.039 & 1 & 0.727 & 1.014 & 0.939 & 1.095 \\
UV Index & 0.069 & 0.047 & 1 & 0.145 & 1.071 & 0.977 & 1.175 \\
Rainfall & 0.325 & 0.216 & 1 & 0.133 & 1.384 & 0.906 & 2.114 \\
constant & 41.653 & 26.315 & 1 & 0.113 & $1.229 \times 10^{18}$ & & \\
\hline
\end{tabular}

Table 4. Univariate logistic regression analysis of the rainfall in different days before the occurrence of tilapia streptococcosis.

\begin{tabular}{cccccccc}
\hline Rainfall & \multirow{2}{*}{ B } & S.E. & df & Sig. & Exp (B) & \multicolumn{2}{c}{$\mathbf{9 5 . 5 \% ~ C . I . ~ E X P ( B ) ~}$} \\
\hline 0 day * & 0.488 & 0.203 & 1 & 0.016 & 1.630 & 1.095 & 2.426 \\
3 day * & 0.406 & 0.201 & 1 & 0.043 & 1.501 & 1.012 & 2.227 \\
5 day & 0.256 & 0.197 & 1 & 0.195 & 1.291 & 0.877 & 1.901 \\
10 day & -0.052 & 0.212 & 1 & 0.806 & 0.949 & 0.626 & 1.439 \\
\hline & & & & &
\end{tabular}

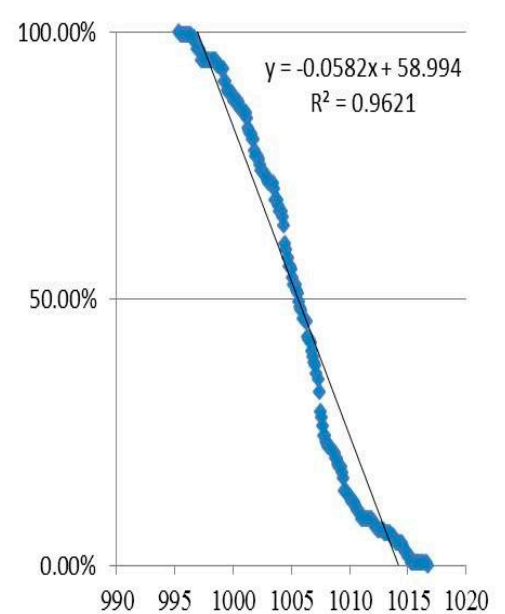

A. average atmospheric pressure

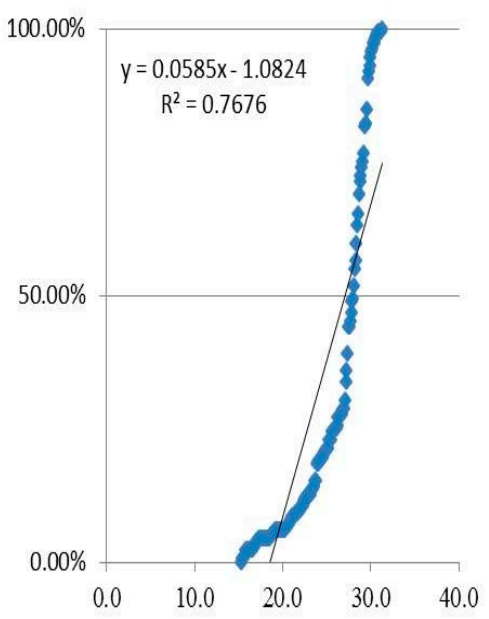

B. average temperature

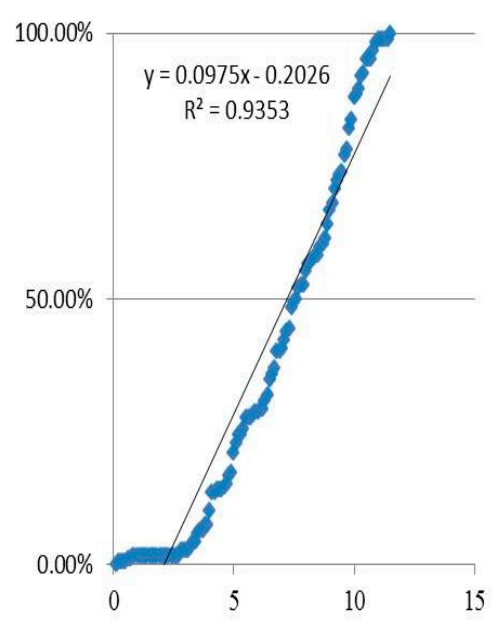

C. UV index

Figure 5. The relations between the percentage of cumulated positive farms from all submitted tilapia cases and climate factors: (A) average atmospheric pressure; (B) average temperature; (C) UV index. When the average temperature is $27.0^{\circ} \mathrm{C}$, the average atmospheric pressure is $1005.1 \mathrm{hPa}$, or the UV index is 7.2 , the percentage of cumulated positive farms from all submitted tilapia cases reached $50 \%$.

\section{Discussion}

\subsection{Fish Diseases Correlation with Climate Change}

Global climate change can affect the ecological settings for pathogens and hosts, involving aspects such as immunity and transmission pathways. Artificial intelligence systems have yet to be used for diagnosis in aquatic animal veterinary clinics around the world. To date, only a few groups have developed useful software programs, e.g., Fish-Vet [21] and Fish-Expert [22]. Studies show that the field of aquatic animal disease is constantly changing and developing [23]. Due to growing environmentally harmful human activities, the concentration of greenhouse gases such as carbon dioxide $\left(\mathrm{CO}_{2}\right)$ and methane $\left(\mathrm{CH}_{4}\right)$ in the atmosphere has increased, leading to an increase in the greenhouse effect, global 
warming, and sea levels, resulting in an imbalance in the ecosystem. Among the climatic factors, correlation between increasing water temperature and risk of fish disease was a diagnostic factor for parasitic infections but not for bacterial or viral infections [11]. A 23-year-long study on the assessment of disease dynamics at a salmon farm in Finland showed that ecological changes, especially changes in temperature, increased the prevalence of the disease caused by Flavobacterium columnare during the high temperature season [24]. Additional research has reported streptococcosis outbreaks to be more closely related to intensive farming, high water temperature (especially summer time), and water quality than the incidence of the pathogen itself $[19,25,26]$.

\subsection{Climate Factor Associated with Tilapia Streptococcosis}

The accumulated infection rate of tilapia streptococcosis in each month showed a peak from July to September, which matched the record of high water temperature period in summers. Similar as previous findings, when the environmental temperature rises, the number of lymphocytes will significantly decrease, causing tilapia to become more susceptible to streptococcal infection [13,27]. A probability mechanism could describe the major response of fish under environmental stress; a strong relation is sensitive to the rise or fluctuation of water temperature and could induce the activation of the hypothalamic-pituitary-adrenal system. Then, it leads to increased cortisol and catecholamine; as neuroregulators may increase, this could next lead to immune suppression [13].

In the present study, low average atmospheric pressure, which usually causes low dissolved oxygen in water, was found to be correlated to streptococcosis in tilapia. A previous report also showed that even at high water temperature $30^{\circ} \mathrm{C}$ or $35^{\circ} \mathrm{C}$, intermittent hypoxia could suppress immunomodulation in vaccinated Nile tilapia against $S$. agalactiae [28]. In Iran, the outbreaks of streptococcosis/lactococcosis in freshwater rainbow trout farms is strongly related with the fluctuation of water temperature and the peak of disease is observed during summer time when temperature is about $16-18^{\circ} \mathrm{C}$. $[29,30]$ Our findings showed that streptococcosis often prevails a few days after raining. Therefore, it is suggested to spread quicklime (calcium oxide) around the fishery pond before raining. Quicklime will then be flushed into the fishery pond when it rains and serves to neutralize and buffer the water affected by acid rain [31,32]. While the temperature and UV index are high, increasing the water stage of the ponds would be a good method to lower the risk of streptococcosis. Other alternatives such as constructing the fish ponds with dipper height, can also lower the risk. In Taiwan, the water volume for tilapia breeding ranges from 250 to $400 \mathrm{~L}$ per kilogram fish weight. As observed in Figure 4, streptococcosis outbreaks in tilapia usually occurr every 3 years. The possible reason is that the increasing in stocking and high density on breeding after the peak on high market price could cause high Streptococcus infection. It is due to increased difficulty of management in the fish production, and also due to an elevated probability of disease spread rate. A previous fishery study also indicated that high-density breeding can cause stress, leading to a decline in disease resistance and a significant increase in streptococcal mortality [8].

\section{Conclusions}

Analyses of climatic factors for tilapia aquaculture farms have been useful in preventing the outbreak of streptococcosis, and therefore are advantageous to veterinary aquatic animal inspection stations in Taiwan. Our research suggests that routine aquatic animal disease surveillance and an early warning model that incorporates risk factors can improve disease management. Indeed, based on our big data in TDS and statistical results, these climatic factors can play a significant role in real-time outbreaks and disease monitoring for tilapia streptococcosis.

Author Contributions: Conceptualization, P.-C.L. and S.-C.L.; data curation, P.-C.L. and Y.-C.C.; formal analysis, Y.-L.T.; funding acquisition, P.-C.W., S.-C.L. and S.-C.C.; investigation, P.-C.L. and Y.-C.C.; methodology, P.-C.L. and Y.-C.C.; software, P.-C.L.; supervision, P.-C.W., S.-C.L. and S.-C.C.; validation, Y.-L.T., P.-C.W. and S.-C.C.; writing-original draft, P.-C.L. and Y.-C.C.; writing-review and editing, Y.-L.T., P.-C.W., S.-C.L. and S.-C.C. All authors have read and agreed to the published version of the manuscript. 
Funding: This research was financially supported by grants of the Council of Agriculture, Taiwan (R.O.C.) (106AS-9.9.3-BQ-B1 and 107AS-8.7.2-BQ-B1).

Conflicts of Interest: The authors of this paper have no financial and no personal relationship with other organizations or personnel that could have influenced the content of this paper inappropriately.

\section{References}

1. Jan, M. The Market analysis of tilapia products of Taiwan. Natl. Taiwan Ocean. Univ. Fish. Promot. 2018, 48, 49-66.

2. Salama, N.K.G.; Murray, A.G. Farm size as a factor in hydrodynamic transmission of pathogens in aquaculture fish production. Aquac. Environ. Interact. 2011, 2, 61-74. [CrossRef]

3. Tung, M.C.; Chen, S.C.; Tsai, S.S. General Septicemia of streptococcal infection in Cage cultured Tilapia, Tilapia mossambica, in Southern Taiwan. COA Fish. Ser. 1985, 4, 95-105.

4. Hoshina, T.S.T.; Morimoto, Y. A Streptococcus pathogenic to fish. J. Tokyo Univ. Fish. 1958, 44, 57-68.

5. Chou, C.C.; LIN, M.C.; Su, F.J.; Chen, M.M. Mutation in cyl operon alters hemolytic phenotypes of Streptococcus agalactiae. Infect Genet Evol. 2019, 67, 234-243. [CrossRef] [PubMed]

6. Chu, C.; Huang, P.Y.; Chen, H.M.; Wang, Y.H.; Tsai, I.A.; Lu, C.C.; Chen, C.C. Genetic and pathogenic difference between Streptococcus agalactiae serotype Ia fish and human isolates. BMC Microbiol. 2016, 16, 175. [CrossRef]

7. Ferguson, H.W.; St John, V.S.; Roach, C.J.; Willoughby, S.; Parker, C.; Ryan, R. Caribbean reef fish mortality associated with Streptococcus iniae. Vet. Rec. 2000, 147, 662-664. [PubMed]

8. Shoemaker, C.A.; Evans, J.J.; Klesius, P.H. Density and dose: Factors affecting mortality of Streptococcus iniae infected tilapia (Oreochromis niloticus). Aquaculture 2000, 188, 229-235. [CrossRef]

9. Kitao, T. Streptococcal infections. In Bacterial Disease of Fish; Inglis, V., Roberts, R.J., Bromage, N.R., Eds.; Blackwell Press: London, UK, 1993; pp. 196-210.

10. Plumb, J.A.; Hanson, L.A. Tilapia Bacterial Diseases. In Health Maintenance and Principal Microbial Diseases of Cultured Fishes; Plumb, J.A., Hanson, L.A., Eds.; Wiley- Blackwell: Ames, IA, USA, 2010; pp. 445-463.

11. Karvonen, A.; Rintamäki, P.; Jokela, J.; Valtonen, E.T. Increasing water temperature and disease risks in aquatic systems: Climate change increases the risk of some, but not all, diseases. Int. J. Parasitol. 2010, 40, 1483-1488. [CrossRef] [PubMed]

12. Marcogliese, D.J. The impact of climate change on the parasites and infectious diseases of aquatic animals. Rev. Sci. Tech. 2008, 27, 467-484. [CrossRef] [PubMed]

13. Ndong, D.; Chen, Y.Y.; Lin, Y.H.; Vaseeharan, B.; Chen, J.C. The immune response of tilapia Oreochromis mossambicus and its susceptibility to Streptococcus iniae under stress in low and high temperatures. Fish. Shellfish. Immunol. 2007, 22, 686-694. [CrossRef] [PubMed]

14. Liao, P.C.; Wang, P.C.; Chen, S.C. Development of aquaculture and animal disease diagnosis and treatment and drug assistance system. Agric. Biotechnol. Ind. Q. 2010, 22, 34-43. (In Chinese)

15. Zlotkin, A.; Hershko, H.; Eldar, A. Possible transmission of Streptococcus iniae from wild fish to cultured marine fish. Appl. Environ. Microbiol. 1998, 64, 4065-4067. [CrossRef]

16. Forsman, P.; Tilsaia-Timisjarvi, A.; Alatossava, T. Identification of staphylococcal and streptococcal causes of bovine mastitis using 16S-23S rRNA spacer regions. Microbiology 1997, 143, 3491-3500. [CrossRef] [PubMed]

17. Hassan, A.A.; Khan, I.U.; Lämmler, C. Identification of Streptococcus dysgalactiae Strains of Lancefield's group C, G and L by Polymerase Chain Reaction. J. Vet. Med. Ser. B 2003, 50, 161-165. [CrossRef] [PubMed]

18. Zlotkin, A.; Eldar, A.; Ghittino, C.; Bercovier, H. Identification of Lactococcus garvieae by PCR. J. Clin. Microbiol. 1998, 36, 983-985. [CrossRef]

19. Jensen, M.A.; Webster, J.A.; Straus, N. Rapid identification of bacteria on the basis of polymerase chain reactionamplified ribosomal DNA spacer polymorphisms. Appl. Environ. Microbiol. 1993, 59, 945-952. [CrossRef] [PubMed]

20. Blaiotta, G.; Pepe, O.; Mauriello, G.; Villani, F.; Andolfi, R.; Moschetti, G. 16S-23S rDNA intergenic spacer region polymorphism of Lactococcus garvieae, Lactococcus raffinolactis and Lactococcus lactis as revealed by PCR and nucleotide sequence Analysis. Syst. Appl. Microbiol. 2002, 25, 520-527. [CrossRef] [PubMed]

21. Zeldis, D.; Prescott, S. Fish disease diagnosis program-Problems and some solutions. Aquac. Eng. 2000, 23, 3-11. [CrossRef] 
22. Li, D.; Fu, Z.; Duan, Y. Fish-Expert: A web-based expert system for fish disease diagnosis. Expert. Syst. Appl. 2002, 23, 311-320. [CrossRef]

23. Brunner, F.S.; Eizaguirre, C. Can environmental change affect host/parasite-mediated speciation? Zoology 2016, 119, 384-394. [CrossRef] [PubMed]

24. Pulkkinen, K.; Suomalainen, L.R.; Read, A.F.; Ebert, D.; Rintamäki, P.; Valtonen, E.T. Intensive fish farming and the evolution of pathogen virulence: The case of columnaris disease in Finland. Proc. R. Soc. B Biol. Sci. 2010, 277, 593-600. [CrossRef] [PubMed]

25. Ismail, N.I.A.; Amal, M.N.A.; Shohaimi, S.; Saad, M.Z.; Abdullah, S.Z. Associations of water quality and bacteria presence in cage cultured red hybrid tilapia, Oreochromis niloticus $\times$ O. mossambicus. Aquac. Rep. 2016, 4, 57-65. [CrossRef]

26. Tavares, G.C.; Carvalho, A.F.; Pereira, F.L.; Rezende, C.P.; Azevedo, V.A.C.; Leal, C.A.G.; Figueiredo, H.C.P. Transcriptome and Proteome of Fish-Pathogenic Streptococcus agalactiae Are Modulated by Temperature. Front. Microbiol. 2018, 9, 2639. [CrossRef] [PubMed]

27. Kayansamruaj, P.; Pirarat, N.; Hirono, I.; Rodkhum, C. Increasing of temperature induces pathogenicity of Streptococcus agalactiae and the up-regulation of inflammatory related genes in infected Nile tilapia (Oreochromis niloticus). Vet. Microbiol. 2014, 172, 265-271. [CrossRef] [PubMed]

28. Wang, J.; Lu, D.Q.; Jiang, B.; Luo, H.L.; Lu, G.L.; Li, A.X. The effect of intermittent hypoxia under different temperature on the immunomodulation in Streptococcus agalactiae vaccinated Nile tilapia (Oreochromis niloticus). Fish. Shellfish. Immunol. 2018, 79, 181-192. [CrossRef] [PubMed]

29. Soltani, M.; Pirali Kheirabadi, E.; Taheri Mirkahead, A.; Shafie, S.H.; Mohamadian, S.; Roholahi, S.H. Molecular study of Streptococcosis/Lactococcosis distribution in farmed rainbow trout in Charmahal-va-Bakhteyari and Kohgiloyeh-va- Boyerahmad Provinces, Iran. Iran. J. Epidemiol. 2013, 9, 59-68.

30. Soltani, M.; Pirali Kheirabadi, E.; Taheri Mirghaed, A.; Zargar, A.; Mohamadian, S.; Roohollahi, S.H.; Zakian, M. Study on Streptococcosis and Lactococcosis outbreaks in rainbow trout farms in Fars and Lorestan Provinces. J. Vet. Microbio. 2015, 11, 49-58.

31. Lazur, A.M.; Cichra, C.E.; Watson, C. The Use of Lime in Fish Ponds; UF/IFAS Extension-University of Florida FA38: Gainesville, FL, USA, 2019; pp. 1-3.

32. Wurts, W.A.; Masser, M.P. Liming Ponds for Aquaculture; SRAC Publication No. 4100: Stoneville, MI, USA, 2013; pp. 1-5.

(C) 2020 by the authors. Licensee MDPI, Basel, Switzerland. This article is an open access article distributed under the terms and conditions of the Creative Commons Attribution (CC BY) license (http://creativecommons.org/licenses/by/4.0/). 